University of Massachusetts Amherst

From the SelectedWorks of Randall Knoper

2007

Trauma and Sexual Inversion, circa 1885: Oliver Wendell Holmes's A Mortal Antipathy and Maladies of Representation

Randall Knoper, University of Massachusetts - Amherst 
Note: This is the version of the essay as it was submitted for publication in Neurology and Literature, 1860-1920, ed. Anne Stiles (New York:

Palgrave, 2007). That is, this is the manuscript version, before copyediting, proofreading, and publication. It is posted here by permission of Palgrave Macmillan.

\section{Trauma and Sexual Inversion, circa 1885: Oliver Wendell Holmes's A Mortal Antipathy and Maladies of Representation}

\section{Randall Knoper}

A mysterious young man appears in a late-nineteenthcentury New England village and inexplicably avoids the young women there, preferring the sole company of his Italian manservant and therefore arousing great curiosity. His secret, as it eventually comes out, is rooted in a childhood shock with sexual overtones and powerful sexual effects. As a baby, while being held and tossed by his beautiful and nubile cousin, he was dropped off a balcony into a thorn bush. The lasting effect of this trauma is that, whenever he is in the presence of a young woman exuding a sexual aura, the natural outward impulse of his nervous system is inverted, turns inward, and arrests his heart. Heterosexual arousal is fatal, and Maurice Kirkwood is thus understandably gynephobic, with an aversion for young women powered by an antipathic neurological response.

This is the plight of the main character in A Mortal Antipathy, published by Oliver Wendell Holmes in 1885 . $^{1}$ Although the novel has fallen into the forgotten territory of decanonized literature, its early, prescient linking of trauma and a kind of sexual inversion demands our attention for what it can tell is about the pathologizing of homosexuality; it inaugurates a strain of thought that still plagues us. I should say at the outset that this fictional case is not one of same-sex desire. But it is, quite literally, a case of inverted sexual impulse, of "sexual inversion"the term used to describe homosexuality. Given that "antipathic sexual instinct" was also used to describe homosexuality, I will argue that Kirkwood's mortal antipathy belongs in the amorphous territory of sexual deviance that included homosexuality and that the sexology of the 1880 s sought to explain. This fictional case helps restore to our historical sense of sexual inversion-and our understanding of the pathologization of homosexuality-a meaning of literal neurological inversion, or reversed nerve force; 
the notion of an "antipathic instinct," as a repulsive neural force akin to the opposite of magnetic attraction, further fleshes out this understanding. But while Kirkwood's fictional case helps clarify the historical conceptions of sexual inversion as a neurological disease, its causal etiology more importantly casts light on the earliest linkage between trauma and supposed sexual deviance. Our pursuit of this link will lead down unexpected routes, into matters of representation and reproduction and into the intertwinings of art and the rapidly developing neuroscience of the late nineteenth century - two areas that Holmes, a poet as well as a Harvard professor of anatomy and physiology, persistently joined.

The novel appeared at a moment when theories of trauma-including the mysteries of psychological trauma-and theories of sexual inversion were proliferating, becoming central concerns of neurologists and alienists, but curiously developing independently of each other. Holmes, seemingly for the first time, brought the two together. No one else appears to have been thinking along the same lines. It was not until 1905 that Sigmund Freud published his Three Essays on the Theory of Sexuality, perhaps the most influential diagnosis of "contrary sexual feelings" and "inversion" as the result of a distressing sexual experience in early childhood. $^{2}$ If our history of the pathologizing of homosexuality as an effect of childhood psychological trauma takes Freud as its strongest point of origin, Holmes's earlier linkage nonetheless tells us something important and different. Specifically, the inspiration behind this combination lay, I will argue, in the connection Holmes made between trauma and sexual inversion as disorders of representation and reproduction, which he thought of analogously. Holmes's innovation provides an instance, that is, of the subtle intertwinings of science and the concerns and metaphorical thinking of art, the ways one can provide grounds for conceiving the other, and the ways the two can join to construct a cultural latticework. Here, thinking metaphorically about representation and reproduction brings about a new etiological explanation at the same time that it helps define a pathology and fix attitudes about sexuality. In turn, neuroscience provides scientific particulars that pathologize sexual inversion as a malady of expression. A Mortal Antipathy, then, serves as a focus and an occasion for unraveling a knot that binds together discourses of shock and sexual deviance, the science of the nervous system, and questions of artistic and biological expression-all tightknit in an ideological configuration that cast its shadow far into the future.

\section{Shock and Memory Circuits}


Before reaching for these conjunctions, though, an overview of the separately developing understandings of psychological trauma and sexual inversion will help situate Holmes's story. And the history of late-nineteenth-century conceptions of psychological trauma must come first. The most familiar reference point for situating the malady of Holmes's protagonist would probably be Sigmund Freud and Josef Breuer's work of the early 1890s, which culminated in Studies in Hysteria in 1895-an apt framework for thinking about A Mortal Antipathy because it made a causal link between childhood sexual trauma and neurosis, specifically hysteria. But of course this work took place some years after Holmes's fictional case, so we must look earlier and elsewhere for context. And in the early 1880s, notions of psychological trauma were emerging especially from the controversy that swirled around "railway spine"—an ailment for which train-accident victims could be granted thousands in damages - and around the questions that railway spine foregrounded about physical and emotional trauma, their differences and their similarities. ${ }^{3}$

The British surgeon John Eric Erichsen, in 1866, had defined railway spine as a physical injury, a supposed "concussion" of the spine resulting in an indiscernible "molecular disturbance"-without a visible lesion-that issued in a range of posttraumatic maladies. His characterization of railway spine was used to support lawsuits against the railroads because it connected the mysterious symptoms many plaintiffs experienced to a concrete bodily injury supposedly suffered in railway accidents. ${ }^{4}$ Controversial from the start, this idea of spinal concussion was notoriously and influentially discounted in the early 1880 s by British railway surgeon Herbert Page, first in an essay that won Harvard University's Boylston Prize and then in his expanded study, Injuries of the Spine and Spinal Cord Without Apparent Lesion, and Nervous Shock, in their Surgical and Medico-Legal Aspects (1883). Page's arguments against the existence of spinal concussion-including his suggestion that the disorders of railway spine may have begun in a trauma-induced hypnotic state that caused dazed victims unconsciously to mimic real physical illnesses, as hysterics did-were used to undermine injury lawsuits. While his study discredited the idea that physical concussion caused railway spine, however, Page brought to the fore the ideas that psychological shock, instead of physical spinal injury, might be the cause of traumatic malady; that "great fear and alarm" alone might cause the common symptoms of shock and might even cause death; and that, indeed, "purely mental causes" might be the best explanation for symptoms that appear in the absence of any apparent physical injury, especially for symptoms 
that surface some time after an accident. ${ }^{5}$ Page certainly was not the first to make the argument that psychological shock can cause physical maladies, but his work became the touchstone for subsequent investigation of the effects of emotional trauma and a locus for thinking about the relation between mind and body. ${ }^{6}$

This emerging argument about trauma, and the possible physical effects of emotional shock, was joined in 1883 and 1884 by Holmes's Harvard colleague, the Massachusetts General Hospital neurologist James Jackson Putnam, along with another physician at the hospital, George L. Walton. They agreed with Page that mental or emotional states could cause posttraumatic symptoms, but they also forwarded the hypothesis that these symptoms were hysterical and, since railway spine most often affected men, that these were cases of male hysteria-or neurasthenia, to avoid the derogatory womanly connotations of hysteria. ${ }^{7}$ Putnam and Walton were strongly influenced by JeanMartin Charcot, whose theories of hysteria were certainly the most prominent at this time, and Charcot in turn cited their work in his own research, as he turned from studying only female hysterics to investigating male hysteria, and from defining hysteria solely in terms of heredity to considering the possibility-tentatively, at least - that it might be psychologically and traumatically triggered. Charcot made his first diagnoses of male hysteria in 1879, published his first article on the topic in 1882, and by 1885, at least, was grappling with cases he believed were induced, if not caused, by emotional trauma. ${ }^{8}$ If he affirmed the existence of male cases precipitated by terror or fright, however, he nonetheless tried to adhere to his somatic model, suggesting that such trauma is still shock in a very literal sense-that is, it translates as electric shock, an electrical impulse that has a physical effect on the nerves. ${ }^{9}$ If spinal concussion is not credited here as the physical cause of posttraumatic symptoms, emotional shock itself becomes a physical cause. Somewhat differently, however, in an argument seemingly spurred by Page's theorizing about trauma victims' hypnotically unconscious mimicry of others' injuries, Charcot in 1884 and 1885 argued that traumatic paralysis differs from organic paralysis because it is caused by an idea, or chain of ideas, set in motion outside consciousness, through hypnosis or suggestion. ${ }^{10}$ Such a notion had its roots in British psychophysiology and its concept of an "ideo-motor" reflex arc, which occurs as a kind of physical brain-body activity outside consciousness. Designed to account for unconscious actions and symptoms in physiological terms, this kind of concept nonetheless straddled the divide between physical and psychological explanations for traumatic disorders. Not due to an organic injury, produced by an unconscious idea, this kind of trauma symptom still operated physiologically. 
Making his fiction part of this medical dispute about the relation between emotional trauma and bodily ailment, Holmes devotes substantial space in his novel-through his mouthpiece, the wise Dr. Butts-to discussing psychological shock as the sole cause of physical maladies. Considering the question of physical versus psychological etiologies of traumatic disturbances, Butts, in accord with Page, declares that a "sudden mental shock" may cause insanity; our asylums can supply many such cases. Even worse, people may die of terror, may be "scared to death, literally." Emotional events do translate into physical states, and, Butts says, "as a violent emotion caused by a sudden shock can kill or craze a human being, there is no perversion of the faculties, no prejudice, no change of taste or temper, no eccentricity, no antipathy, which such a cause may not rationally account for." Musing on Kirkwood's antipathy before he learns the full truth, Butts thinks to himself that "some early alarm" may have "broken some spring in this young man's nature, or so changed its mode of action as to account for the exceptional remoteness of his way of life" (MA, 91-92). In line with Page, Putnam, and Walton, then, Holmes endorses the idea that shock in the sense of emotional or psychological trauma - a fright, an alarm — can be the cause of multiple pathologies and can have material bodily effects, from creating an antipathy to causing death.

But in what we might consider an elaboration of Charcot's distinction between traumatic paralysis and organic paralysis, Holmes then makes a distinction in the causal mechanism between simply physical and psychological origins. Talking about antipathies and aversions, Butts says that when people faint at the sight of blood, or have spasms or fits of sweating when they hear certain sounds, such cases of "profound disturbance of the nervous system" are "produced by impressions on the organs of sense, seemingly by direct agency on certain nerve centres" $(M A, 89)$. It is as if sensory perception is a kind of physical agency whose force makes a material impression directly on a nerve-center, causing the "disturbance" as if it were a sensorimotor reflex action-in a way similar to Charcot's materialization of shock as an electrical impulse. Butts distinguishes, however, between this and "another series of cases in which the imagination plays a larger part in the phenomena" $(M A, 89)$. Peter the Great, as an infant, fell from a bridge into the water, and ever after dreaded the sound of wheels on a bridge. Another man, when an infant, had a shock when the cord supporting a weight in a clock broke, and the weight came crashing down in the case; ever after, when he passed a tall clock, he experienced profound nervous agitation. While Butts still speaks of the initial trauma in these cases in terms of material mechanism, as instances in which "Some effect must have been 
produced upon the pulpy nerve centres from which they never recovered" $(M A, 91)$, the differentiating function for these victims, as for Maurice Kirkwood, is that of imaginative associationbetween a remembered trauma and wheels on a bridge, or clocks, or young women. A present perception triggers a memory associated with the trauma, and the original nervous turbulence is reproduced. Notably, Holmes's version of this associationism is physiological. Articulated in the vocabulary that had developed in the 1860s of neural pathways, the conception of imaginative association bears importantly on the prospects for curing Kirkwood.

But the complications in Holmes's fictional effort to assay the kinds and effects of shock get additional turns of the screw that go beyond this uncertain territory of mind-body intermingling. Specifically, he invokes two theories about the effect of shock on bodily energy-its stifling of vital force or its reversal of nervous energy - that more particularly describe Kirkwood's sexual economy. Both theories draw upon understandings of inhibition as part of the regulatory operation of the nervous system. In the first, shock causes a reflex depression of vital force. Ever since the eighteenth century, as historian Roger Smith notes, there had been a notion of "spinal shock" —in which shock works to inhibit reflex action, so that in the case of a decapitated frog, the animal's spinal system would not resume reflex function until some time after the brain had been destroyed. ${ }^{11}$ Herbert Page had similarly entertained the idea of shock as a "reflex paralysis" or "reflex inhibition" that involved "a lowering of the vitality of every organ and function of the body" (ISSC, 144-45). Such reflex inhibition suits the condition of Maurice Kirkwood, not only because the reflex action of his heartbeat is stayed by the shock, but also because he suffers the "sudden collapse of all the powers of life" $(M A, 231)$. In these terms, shock might be an inhibition simply in the sense of a reflex depression of nerve-force, a lowering of vital force, a stanching of the well of life.

But another conception of shock as causing a reversal of nerve force surfaces in these discussions of the 1880s. British surgeon John Furneaux Jordan, invoking the theory of the correlation and convertibility of force, argued that shock could not be a depression of nerve force, because "no force can be depressed; it can only be metamorphosed into some other of the numerous forces which prevail, or are capable of prevailing, in the animal economy." Shock, then, "is essentially a metamorphosis of nerveforce" (SASO, 42). ${ }^{12}$ Page endorsed Jordan's idea and further suggested that, in a metamorphic reversal of force, people with greater nerve force will suffer greater effects of shock (ISSC, 15456 ); the abundance of nervous energy in such victims is not simply 
stifled but is actively turned against them as an inhibitory force. In an elaboration of the idea, which resonates especially well with Kirkwood's case, Jordan focuses on the effects of shock on the heart, which he considers a primary focus and gauge of shock (SASO, 22). In his conception-attuned to the advances being made in the 1880s, especially by physiologists at Cambridge University, in understanding the regulatory system of the heartnervous reflexes both excite and inhibit the heartbeat, acting in an equilibrium of antagonistic forces to control heart rate. ${ }^{13}$ Specifically, the "pneumogastric" nerves "retard or inhibit cardiac action," while "the sympathetic stimulates the heart to increased action" (SASO, 44). Just as nerve force, then, can be metamorphosed from an inspiriting agency to a depressive one, so can it both stimulate heart rate through the sympathetic nerves and slow or arrest the heart through the pneuomogastric nerves.

These conceptions of shock suit the condition of Maurice Kirkwood, partly because it is his reproductive impulse, the fundamental "spring" of vitality, that is depressed, and partly because that strong impulse has indeed been metamorphosed through shock into an equally strong reversed force, an imbalanced "reflex inhibition" that has "so changed its mode of action" as to turn its energy against life, to snuff it out rather than help it bloom. Even more particularly, a medical report on Kirkwood to the Royal Academy of the Biological Sciences asserts that his case is one of "the effect of inhibition on the heart." In a kind of summary of the then-current knowledge about reflex regulation of the heartbeat through excitation and inhibition, the report explains that one group of nerve cells "acts as the spur" on the heart, accelerating it, and another "as the bridle," retarding it. A "disturbed" influence of "the centre of inhibition"_ as "the restraining influence over the heart is called"-is the usual cause of "well-known cases of deadly antipathy" (MA, 235-236). In accord with these understandings of shock, Kirkwood's initial emotional trauma exaggerates an inhibitory reflex action that arrests his heart. A nerve force that normally operates in a regulatory balance with the enlivening stimulus gains the upper hand. And now the presence of any young woman opens the associational pathway that reactivates this inhibitory, death-dealing power, opposing vitality itself.

The final significant context for understanding the operation of Kirkwood's traumatic memory is the later nineteenthcentury reconceptualization of association. Associationism, of course, had been one of the dominant philosophical-psychological conceptions of how the mind worked, stemming especially from the writings of John Locke and then James Mill. In the latter half of the nineteenth century, various theorists, notably Alexander Bain and Herbert Spencer, worked to "physiologize" 
associationism, attempting to match conceptions of mental association to developing knowledge about the nervous system and the brain. ${ }^{14}$ As neural pathways were traced in the 1860s and 1870 s, this anatomical knowledge combined with understandings of electrical science that allowed modeling of mental associations and memory in terms of intense or repeated electrical flows down neural pathways. Théodule Ribot's The Diseases of Memory, published in 1881 and translated into English in 1883, synthesized and summarized this physiological thinking about memory and became a touchstone. For Ribot, memory was "essentially a biological fact, and only by accident a fact of psychology," and more particularly, it was "not a collection of impressions, but an assemblage of dynamic associations." ${ }^{15}$ These associations, which were physical flows between nerve cells, he compared to muscular actions, which become ingrained habits over time; repetition likewise established the persistence of memory, as the flows of association established their traces, thereby encouraging nerve force to stream down their channels. As Francis G. Gosling observes, "Images of ruts, channels, and paths appear regularly" in the neuroscience of this period, "based on the concept that repeated actions along certain nerve paths eventually made it unlikely that impulses would travel any other route, much like the process of feet wearing a path across a lawn." Such a worn path constituted a durable memory. Assuming, relatedly, that pathologies were due to "morbid" channelings or "pernicious" pathways, therapies were developed to disrupt such habitual neural functioning-by, say, a change of scenery, which could establish new associations and pathways. $^{16}$

Maurice Kirkwood's fatal association between his childhood trauma and sexually alluring young women conforms to these physiological ideas about memory. After the accident, when his cousin Laura approached him, Kirkwood reports, "the dread that she was about to lay her hand upon me had called up the same train of effects which the moment of terror and pain had already occasioned"-which included the arrest of his heart $(M A, 209)$. As he further explains, "It was too evident that a chain of nervous disturbances had been set up in my system which repeated itself whenever the original impression gave the first impulse" (MA, 211). And the original impression extends beyond Laura to all women of her age. Because Kirkwood will feel mortal effects when he is simply near a young woman, even if he does not know she is there, Dr. Butts hypothesizes that she may emit an electrical or magnetic "effluence" that triggers the mortal response (MA, 242). Holmes, however, in his preface to the novel, explains that there are especially strong associations between the olfactory nerves and those of "the higher organs of consciousness." In 
Kirkwood's case, the odor, or "atmosphere," of his sexually ripe cousin - and of any woman of her age and condition-became associated with his traumatic fall. As Holmes puts it: "It was an atmospheric impression of this nature which associated itself with a terrible shock experienced by the infant ... . The impression could not be outgrown, but it might possibly be broken up by some sudden change in the nervous system effected by a cause as potent as the one which had produced the disordered condition" (MA, 217). Kirkwood is left "with an unconquerable fear of woman at the period when she is most attractive not only to adolescents, but to children of tender age, who feel the fascination of her flowing locks, her bright eyes, her blooming cheeks, and that mysterious magnetism of sex which draws all life into its warm and potently vitalized atmosphere" (MA, 213); as the report to the Royal Academy of Biological Sciences notes, he has no such reaction to "an old withered crone" and has a "timid liking for little maidens" $(M A, 231)$. Finally, that report elaborates on his case in a way that echoes conceptions of associations as neural pathways, and that explains how this neural connection between trauma and young women then works to stop Kirkwood's heart:

A single impression, in a very early period of atmospheric existence, . . . may establish a communication between this centre [the center of inhibition in the brain] and the heart which will remain open ever afterwards. How does a footpath across a field establish itself? Its curves are arbitrary, and what we call accidental, but one after another follows it as if he were guided by a chart on which it was laid down. So it is with this dangerous transit between the centre of inhibition and the great organ of life. If once the path is opened by the track of some profound impression, that same impression, if repeated, for a similar one, is likely to find the old footmarks and follow them. Habit only makes the path easier to traverse, and thus the unreasoning terror of a child, of an infant, may perpetuate itself in a timidity which shames the manhood of its subject." (MA, 236)

The report leaves open the possibility that there can be a remedy for this perverted current, a redirection of its flow into "natural" channels-which, as we shall see, leads to Kirkwood's cure. But first let us attend to the other context for this condition, the heterosexual timidity that shames one's manhood, the sexual dysfunction associated with Kirkwood's odd behavior.

\section{Inverted Sexual Feeling}

None of our histories of the invention and psychologization of trauma has anything to say about sexual inversion-theories of which, I will argue, inform Holmes's representation of Kirkwood's 
gynephobia. Sexual inversion, rather, fits into another history, now also beginning to seem solidified and familiar, a history of the medicalization of homosexuality. ${ }^{17}$ As such scholars as Harry Oosterhuis and Vernon A. Rosario tell it, the important moments in this history include the 1869 article on conträre Sexualempfindung by Karl Westphal, the editor of the German Archives of Psychiatry and Nervous Diseases, which was followed by a flurry of publications in Germany on "contrary sexual feeling," culminating in an 1877 essay on the subject by Richard von Krafft-Ebing-who would call his compendious life-work Psychopathia Sexualis, with Especial Reference to the Antipathic Sexual Instinct (1886). ${ }^{18} \mathrm{~A}$ group of physicians in the United States also wrote on the topic in the early 1880s. ${ }^{19}$ In a way similar to studies of hysteria written in the late nineteenth century, these essays on "perverted sexual instinct" tend to refer to their topic as a hereditary neuropsychopathic condition, not as something acquired. And they mix various kinds of cases together-those of clear same-sex erotic attraction, but also instances of gender-identity inversion and transvestism. Exactly what antipathic or inverted sexual instinct meant is often unclear, as are the specific etiologies. An "organic brain defect," "congenital perversion of the sexual instinct," "a disease of the central nervous system," "hereditary taint," a "perversion somewhat analogous to hysteria," a nervous father, a hysterical mother-all these conditions or causes are mentioned as ways of explaining the patients' sexual deviations. ${ }^{20}$

In 1882, Charcot and his colleague Valentin Magnan entered the discourse with their essay "Inversion du sense génital" (building on the conception of "inversion of the sexual instinct," introduced in 1878 by the Italian doctor Arrigo Tamassia). ${ }^{21}$ Curiously, however, Charcot does not mingle his interest at that time in trauma with this new subject of sexual inversion. ${ }^{22}$ The article apparently was written primarily by Magnan, and its etiology of the "inversion of the genital sense" is invariably congenital and based on Magnan's theory of hereditary degeneration. Charcot never wrote again on inversion. Magnan did, developing an etiology of sexual disorders that located their causes at particular spots in the nervous system; the problems emanated from "primitive" cerebrospinal levels, thus making deviant sexual desires into degenerate, involuntary reflexes for which the sufferers were not responsible. This work instigated a flurry of interest by 1885 , especially in the French medical journals, as systems were proposed to define and classify "antipathic" or "contrary" or "inverse" "sexual instinct" or "genital sense." 23 For the most part, the etiology remained that of hereditary, sometimes degenerative, taint. In a moment of near contact between theories of trauma and sexual inversion, while 
Magnan worked out his nosology of sexual deviance, he did entertain the possibility that mental disease generally could be due to trauma rather than inherited nervous system weakness. ${ }^{24}$ But again, as with Charcot, the interest in sexual inversion and the interest in trauma did not make explicit connection.

One might argue that Holmes actually does not make the connection either, because the sexual inversion that Kirkwood's trauma leads to does not really suit the medical definitions, especially to the extent that they describe same-sex desire or explicit homosexuality. Kirkwood, after all, is attracted to young women. He says they "at once attracted and agitated me," but when near one there comes a sense of impending death, his circulation feels paralyzed, he feels faint (MA, 214-217). He laments his condition: "After all, what had I to live for if the great primal instinct which strives to make whole the half life of lonely manhood is defeated, suppressed, crushed out of existence?" (MA, 223). Also, Dr. Butts likens the problem to that of a young man who loses all confidence in the presence of the very woman to whom he is most attracted $(M A, 246)$, and the report to the Royal Academy of Biological Sciences similarly wonders if, instead of being anomalous, Kirkwood's condition is "only the last term of a series of cases which in their less formidable aspect are well known to us in literature, in the records of science, and even in our common experience" (MA, 231)—thereby seemingly drawing Kirkwood into the continuum, or bell curve, of the heterosexually normal.

On the other hand, his malady "was a reversed action of the nervous centres,--the opposite of that which flushes the young lover's cheek and hurries his bounding impulses as he comes into the presence of the object of his passion" (MA, 215). And we are told that "the natural current of the instincts has had its course changed as that of a stream is changed by a convulsion of nature, so that the impression which is new life to you is death to him" $(M A, 225)$. By calling the condition the opposite of the heterosexual norm, and by using the language of inverted "instinct" and antipathic instinct, Holmes seems to bring Kirkwood's case into the realm of sexual inversion, where the opposite of heterosexuality may be a death-drive reversal of the reproductive impulse, or an inverted "polarity" which, as the opposite of the male-female, plus-and-minus electrical attraction, suggests something other than heterosexual eccentricity. It is worth noting, too, that the medical articles on sexual inversion refer to men who had "a feeling toward females . . o of indifference or repugnance," 25 a "horror feminae," ${ }^{26}$ a "disgust for women," 27 "a real dislike for girls" and "a horror of women," 28 and so on. These men, unlike Kirkwood, also experienced same-sex desire. But their similar 
antipathy toward women draws Kirkwood into their orbit. One case, reported in 1883 by William A. Hammond, former surgeon general of the U.S. Army and president of the American Neurological Association, sounds very much like Kirkwood's type: the patient was "a young man of twenty years of age, a graduate of college, of an aesthetic turn of mind . . . who condemned himself to solitude, who fled from the world and exhibited the most decided repulsion, not only toward women in general, but towards all that could exhibit the least evidence of a feminine origin . . . ." This young man also was excited by pictures of naked men. ${ }^{29}$ But again, all outward, public signs match him nicely to Kirkwood.

Moreover, for Kirkwood there is significant guilt and shame associated with his condition. When as an adolescent Kirkwood goes to Italy, to consider enrolling in a Catholic boys school in order to avoid women, he gladly accepts from a friend a medal, blessed by the Pope, which is supposed to draw out "original sin" as well as "evil and morbid tendencies," though finally it does not change his "unnatural condition" (MA, 218). What exactly might he be viewing in himself as an evil and morbid tendency, in need of religious repair? A bit more explicitly, Kirkwood is finally brought to reveal his secret "for the light it throws on certain peculiarities of human character often wrongly interpreted as due to moral perversion, when they are in reality the results of misdirected or reversed actions in some of the closely connected nervous centres" $(M A, 223)$. Is this meant to say that his condition is not a moral perversion, such as same-sex desire might be thought to be, but rather a nervous malady? Or is it meant to say that whatever his condition, again perhaps something that looks like same-sex desire, it is not a moral shortcoming but rather a physiological malady? Although Holmes clearly wants to absolve his protagonist of responsibility for any "evil" or "moral perversion," he also seems to want to invoke, and account for, sexual differences that can be seen as such. Finally, there is an echoing subplot about a female student who qualifies as a neuropathic gender invert, and who therefore throws Kirkwood's similar status into sharper relief. Lurida Vincent is a suffragist $(M A, 94)$ who declares that she doesn't like men much, because they are tyrants, and that women could get along better without them $(M A, 283)$. She is an advocate of "virile womanhood," of the Amazonian kind, though she herself is scholarly rather than virilely muscular $(M A, 40)$. Indeed, the regular "over-excitement" of her brain tends to sap her "vitality" $(M A, 77)$. She keeps her hair short, partly because "Her head used to get very hot when she studied hard," as if all the required nervous force was radiating into the atmosphere $(M A, 124)$. Her penetrating curiosity about Kirkwood leads her to want to study medicine (MA, 104), and most 
particularly she wants "to study up the nervous system, and learn all about it" (MA, 126), though there is the suggestion that she wants this knowledge to explain her own debilitated system, as well as to penetrate Kirkwood's. We learn that Lurida's "brain had run away with a large share of the blood which ought to have gone to the nourishment of her general system," so she doesn't have the "womanly developments" that the heroine of the novel, Euthymia, has. In Lurida's case, "An impoverished organization carries with it certain neutral qualities which make its subject appear, in the presence of complete manhood and womanhood, like a deaf-mute among speaking persons" (MA, 255-56). In other words, Lurida's vital force is wrongly channeled into intellectual pursuits, thereby foiling its natural physical expression in her body; the simile of the deaf-mute is telling, because it figures Lurida as a failure in selfexpression. She does have a voice, though, which is "penetrative, aggressive," and expresses "the corresponding traits of mental and moral character" $(M A, 145)$. But if she suceeds in that kind of masculine self-expression, we also must note that her brain demands so much blood that she cannot even blush when embarrassed-and thus is deprived of the exemplary outward expression of unmediated and sincere female modesty $(M A, 132)$.

She is implicitly contrasted to Maurice: for example, she has a "bold, almost masculine" style of handwriting (MA, 118), while Kirkwood's is "not decisive" ( $M A, 95)$. In voice, body, failure to blush, and habitual gesture-the natural physical expressions of the inner person-Lurida shows herself a failure in "complete womanhood." As a foil to Maurice Kirkwood, she mirrors his condition of deviantly channeled nervous energy, energy that does not move sexually outward towards new life. She also quite clearly represents a gender inversion. Paired as they are, Lurida and Maurice underscore this story as one of sexual inversion, even if neither is explicitly homosexual.

\section{Maladies of Representation and Their Cures}

This, then, is the framework for A Mortal Antipathy. But if this context of scientific discourse about psychological trauma and sexual inversion helps us to understand Holmes's novel, it still does not explain why Holmes was "ahead" of cutting-edge neurology and psychology in thinking about, and joining, these matters-in pathlogizing sexual inversion in a new way, as an acquired trait caused by trauma. Now, it may be apparent from the foregoing discussion that analogical connections between trauma and sexual inversion were ready at hand. If shock was conceived as a depression of nerve force or life force, or if it was conceived as an exaggeration of inhibitory nerve force over stimulative, then it 
could logically enough join sexual inversion as an upending or derailment of vitalilty, a foiling of the life force that would otherwise attain its ultimate goal in reproduction. The neural inhibition of shock and the reversal of the heterosexual impulse in inversion would be matched as antilife forces, a conclusion that is easy and familiar enough. But I think there are additional complications in Holmes's thinking about the matter which come from his bundling together notions of biological reproduction, the nature of life to express itself, and the natural truthfulness of such expression when it follows its "proper" channels. I suggest, that is, that Holmes's twinned vocations as physician and creative writer impel his logic, bringing questions of biological reproduction and and truthful representation together in such a way that they provide grounds for joining trauma and sexual inversion.

Trauma would be for Holmes a disorder of representation partly because (as with hysteria) its symptoms do not plainly lead to its causes - a dynamic clear enough in this novel from the extended puzzlement and ruminations of Lurida Vincent and Dr. Butts over Kirkwood's ailment. It would also disorder representation because the traumatic memory derails truthful representation of the present - as the frightful image from the past, in Kirkwood's case, now impedes the present apprehension of a beautiful woman. That is, trauma does not directly register itself, and in turn it deranges the body's natural process of registering and representing reality; the channels of expression and communication are perverted. In this case, as well, trauma as a malady of representation causes another malady of representation, sexual inversion. Obviously enough, as I have suggested, sexual inversion is a disorder of representation because it disarranges the natural outward expression of life, of life force, of sexual energyand it of course foils reproduction. Indeed, both trauma and sexual inversion here impede hereditary transmission by disrupting the natural flow of human life-expression, of species selfrepresentation. The anchoring particular that joins these ailments is an impediment or diversion in the expressive flow of life force. We ultimately see in A Mortal Antipathy a push toward a horizon of meaning where trauma and sexual inversion join as opposites of self-representation in both its communicative and biological senses. And this ground for their similarity-the way they work analogously, almost homologously, to impede natural expressionreappears in their cure, as I shall explain in a moment.

Kirkwood's cure intriguingly echoes the therapy of cathartically re-experiencing trauma that Freud and Breuer would later develop, which once again raises the question of where Holmes might have gotten the idea. Holmes's cure draws on several other strands of thinking about trauma and the nervous 
system, however. First, the report to the Royal Academy of Biological Sciences had suggested that Kirkwood's unnatural neural circuit could be "made to change its course, so as to follow its natural channel," possibly through "some sudden, unexpected impression," though the restoration of his "true nature" might require "as energetic a shock to displace it as it did to bring it into existence." For example, "If he were drowning, and a young woman should rescue him, it is by no means impossible that the change in the nervous current we have referred to might be brought about as rapidly, as easily, as the reversal of the poles in a magnet" (MA, 237-39). Such a cure involves a revision of the traumatic imprint, a re-righting of the perverted physical structure of neural pathways. And Kirkwood is indeed cured in a similar scenario. While sick, and asleep, he has a nightmare that he is deep in a coal mine, then that he is climbing a sheet of ice above an abyss, and then that the abyss is a volcano whose smoke is smothering him. At that, he awakens to realize the house is on fire. Paralyzed with fear, expecting death, he recalls his life-memories and, in particular, "The dread moment which had blighted his life returned in all its terror. He felt the convulsive spring in the form of a faint, impotent spasm,--the rush of air,--the thorns of the stinging and lacerating cradle into which he was precipitated" (MA, 263-66). This time, however, the narrative of the trauma is revised, as the heroine of the novel, Euthymia, rushes into the burning house and carries Kirkwood out "as easily as if he had been a babe." Outside, she holds him on her bosom, he hears her heart and feels her breathing, and she becomes associated with life rather than death $(M A, 273-75)$. She causes "a revolution in his nervous system" $(M A, 277)$, his "vital currents" are redirected, and his "disturbed, perverted instincts" are rerouted into "their natural channel" (MA, 281). The result: "The river which has found a new channel widens and deepens it; it lets the old water-course fill up, and never returns to its forsaken bed. The tyrannous habit was broken" $(M A, 279)$. The repeated story and its neural pathway have a new ending. Cradled like a babe, and reverting to his babyhood trauma, Kirkwood is reborn, freed from the image ingrained in the nervefibers of his memory.

One might argue that, rather than a cathartic-reliving remedy, this cure more closely resembles the therapy of revising a traumatic memory through hypnotic suggestion, which Pierre Janet was soon to recommend. That is, in his thesis L'Automatisme Psychologique (1889), Janet, who believed in the psychogenesis of traumatic hysteria, describes cases in which neurotic patients who have suffered trauma are taken back through hypnotism to the moment of trauma, and then have the traumatic memory erased and replaced by hypnotic suggestion. For example, a patient who 
as a child saw an old woman fall down the stairs and die, and has hallucinatory relivings of the terror she felt, is taken back to the moment, and told that the old woman did not die. As Janet put it, after bringing the patient back "to the moment of the accident, I was able, not without difficulty, to change the mental image, to show her that the old woman had only stumbled and not killed herself, and efface the terrifying idea: the attacks of terror did not recur." He modifies or effaces the mental images from the moment of trauma, and thus accomplishes a cure by revising the patient's past. $^{30}$ Writing of the development of this process, Henri Ellenberger credits Janet with the first case of a cure through reliving a trauma - in work undertaken in 1888, and published in his thesis of 1889; Holmes's earlier fictional cure of course wouldn't count as a therapeutic breakthrough, but its precedence is astonishing. Malcolm Macmillan notes that the Belgian psychophysicist J. R. L. Delboeuf, also in 1888, used hypnotism in a very similar way to have a patient relive and expel a traumatic memory. According to Delboeuf, maladies can arise from a "suggestion" occurring at the traumatic moment; to effect a cure, the hypnotist "puts the subject back into the state in which his trouble manifested itself and combats with the spoken word the same trouble, but in a state of rebirth." ${ }^{31}$ Both of these procedures assume that the patients, plunged into a traumatic state akin to the hypnotic state, had a fixed, pathological idea implanted in their memory; the cure was to use hypnotic suggestion to replace the idea.

Relatedly, the American author Edward Bellamy, who would become famous in 1888 for his novel Looking Backward, had published in 1880 a novel called Dr. Heidenhoff's Process, whose titular process was named "thought extirpation." On the principle that memories are stored in certain groups of "nerve corpuscles or fibres in the grey substance of the brain," and that these fibers and the memories they contain can be destroyed without affecting the rest of the brain, Dr. Heidenhoff applies galvanic current as a way of "obliterating the obnoxious train of recollections." Though he is able only to ablate morbid or diseased fibers, made so "by excessive indulgence of any particular train of thought," he foresees a day when "the mental physician will be able to extract a specific recollection from the memory as readily as a dentist pulls a tooth." The heroine of the novel, who wants to be freed from the memory and shame of having been seduced and abandoned, is told to "fix your attention on the class of memories which you wish destroyed; the electric current more readily follows the fibres which are being excited by the present passage of nerve force." The process works - until the surprise ending, when the hero awakes, realizes Dr. Heidenhoff's process was all a 
dream, and receives a letter from the heroine announcing that her shame will indeed be washed away, by her death, apparently by her own hand. ${ }^{32}$ Bellamy's story preceded Holmes's novel, and Holmes undoubtedly knew it. But Heidenhoff's process has a similarity to Janet's and Delboeuf's which makes it fundamentally different from the process Maurice Kirkwood goes through: all these therapies provide cure or rebirth by forcing memory into misrepresentation, or by destroying truthful memory traces altogether.

As Ian Hacking has observed, Janet's therapy was not one of helping patients see the truth about their illnesses. The obscured, the hidden, was not revealed. Rather, the malleability of memory was exploited so that the image of the actual past was replaced by a curative fiction, a misrepresentation. ${ }^{33}$ This decidedly is not the thrust of Holmes's cure. Rather, for Kirkwood, his "true" and "natural" self has been written over by his trauma. The natural expression of his life force has been impeded, or channeled off in the wrong direction. The cure is to enable the natural upsurge of vital force, an upsurge conflated with a sexual outflowing of nervous energy, culminating in biological reproduction. This release of vital nerve force is the true expression of Kirkwood's manhood and the vehicle for its reproduction. To drive this point finally home, Holmes has Kirkwood and Euthymia get married and produce a son, and Holmes ends his novel with a test. Partly curious to see if his antipathy to his cousin Laura is fully gone, but more interested to see if he may have passed his antipathy down to Maurice, Jr., Kirkwood invites Laura to come see them. Happily, Laura elicits fear from neither father nor son $(M A, 303-305)$. In the scientific world, this of course would be a repudiation of the still-pervasive Lamarckian notion that an acquired trait could be passed down to one's offspring. In Holmes's logic of expression, reproduction, and representation, it also means that, now that the perversion/impediment is removed, the hereditary sequence that naturally reproduces the image of the father in the son is restored, unmarked by any registration of trauma. The traumatic sexual inversion is cured by freeing the natural expression of life, by lifting the impediment, the nebula, to allow the outflowing of truthful human nature.

In A Mortal Antipathy, trauma and sexual inversion thus become a pair, imagined that way because they are maladies of representation, enemies of the true expression of life force. We see here an instance of literary imagining that foretells directions of scientific investigation-uncannily preceding Freud's 1890s work on sexual trauma and neurosis, the "antipathic instinct" of KrafftEbing's Psychopathia Sexualis (1886), the therapeutic re- 
experiencing of trauma that Janet and Freud would soon explore, and the much-later theorizing about homosexuality as caused by trauma. Holmes's precognition happens, I suggest, because this literary imagining crystallizes larger frameworks of meaning that can help us better understand and explain the trajectory of both scientific and cultural formulations and that can help us see, in this case, the ideas afloat-about neural force, reproduction, and species self-expression-that would lead to a pathologizing of sexual inversion. It helps us see how the very definition of sexual inversion would lead to its stigmatization as the opposite of healthy self-expression and reproduction. In short, we have a literary investigation that illuminates the long history of homosexuality pathologized as a wounding, and that foregrounds the formative assumptions that lay behind this conceptualization-assumptions that lurk behind similar pathologizations today. Biological theory here becomes intertwined with the theory of representation, and a science that pathologizes sexual inversion supports an emergent literary realism, which supports that science in return.

${ }^{1}$ Oliver Wendell Holmes, A Mortal Antipathy, $3^{\text {rd }}$ ed. (Boston: Houghton, Mifflin, 1886). Further references will be cited parenthetically in the text as $M A$.

${ }^{2}$ Sigmund Freud, "Three Essays on the Theory of Sexuality," in Peter Gay, ed., The Freud Reader (New York and London: W. W. Norton, 1989), 239-93, 241, 243, 244.

${ }^{3}$ Jane F. Thrailkill, in her forthcoming book, Affecting Fictions: Mind, Body, and Emotion in American Literary Realism (Cambridge, Massachusetts: Harvard University Press, 2007), similiarly situates $A$ Mortal Antipathy in relation to the arguments about railway spine-as part of her general argument that we should renew our attention to the ways nineteenth-century writers conceived of embodied emotion. Although the particulars of our arguments and contextualizations differ, we fundamentally agree that in his thinking about "shock" Holmes productively focused on the uncertain territory between corporeal etiologies and emotional etiologies.

${ }^{4}$ See Ralph Harrington, "The Railway Accident: Trains, Trauma, and Technological Crisis in Nineteenth-Century Britain," http://www.york.ac.uk/inst/irs/irshome/papers/rlyacc.htm, for a full history of railway spine and the explanations for it, from anatomical, to physiological, to psychological; Harrington gives special and full attention to John Eric Erichsen's and Herbert Page's developing theories. Also see Jill L. Matus, "Trauma, Memory, and Railway Disaster: The Dickensian Connection," Victorian Studies 43, no. 3 (2001), 413-36 and Matus's essay in this volume, "Emergent Theories of Victorian Mind Shock: From War and Railway Accident to Nerves, Electricity, and Emotion." For a history of railway spine on the American scene, see Eric Caplan, Mind Games: American Culture and the Birth of Psychotherapy (Berkeley, Los Angeles, London: University of California Press, 1998), 11-36. And for a more general account of the 
psychologization of trauma see Ian Hacking, Rewriting the Soul: Multiple Personality and the Sciences of Memory (Princeton, New Jersey: Princeton University Press, 1995), 183-96.

${ }^{5}$ Herbert W. Page, Injuries of the Spine and Spinal Cord Without Apparent Lesion, and Nervous Shock, in their Surgical and MedicoLegal Aspects (London: J. \& A. Churchill, 1883), 147-8; further references will be cited parenthetically in the text as ISSC. Holmes had also won the Boylston Prize, had served on the judging committee, and would undoubtedly have read Page's work. See Eleanor M. Tilton, Amiable Autocrat: A Biography of Dr. Oliver Wendell Holmes (New York: Henry Schuman, 1947), 140-2, 144-6, 185.

${ }^{6}$ For a considerably earlier example, see Russell Reynolds, "Remarks on Paralysis and Other Disorders of Motion and Sensation, Dependent on Idea," British Medical Journal 2 (1869), 483-85, which argues that disorders of the nervous system could be caused by an emotion or an idea and the effects of shock after railway accidents are instances of this (484). Ralph Harrington notes that Frederic Le Gros Clark in 1868 and John Furneaux Jordan in 1873 also took psychological shock into account as a cause of railway-accident maladies. Arguing more generally for the effect of the mind on the body, Henry Maudsley in 1870 told the Royal College of Physicians that "A sudden and great mental shock may, like a great physical shock, and perhaps in the same way, paralyze for a time all the bodily and mental functions, or cause instant death" (Body and Mind, rev. ed. [New York: Appleton, 1885], 38-9). ${ }^{7}$ See James J. Putnam, "Recent Investigations into the Pathology of Socalled Concussion of the Spine," Boston Medical and Surgical Journal 109 (1883), 217-20, which argues against the diagnosis of spinal concussion and for that of hysteria; J. J. Putnam, "The Medico-Legal Significance of Hemianaesthesia After Concussion Accidents," American Journal of Neurology and Psychiatry 3 (1884), 507-16, which focuses on male patients and suggests a diagnosis of "neurasthenia," partly because hysteria has come to suggest "exaggeration, womanishness, and deception" (512); G. L. Walton, "Case of Typical Hysterical Hemianesthesia in a Man Following Injury," Archives of Medicine 10 (1883), 88-95, largely about treatment with magnets, but also occupied with male subjects; and G. L. Walton, "Case of Hysterical Hemianaesthesia, Convulsions and Motor Paralysis Brought on by a Fall," Boston Medical and Surgical Journal 111 (1884), 558-9, which stresses hysterical symptoms brought on by emotional trauma. Also see Caplan, Mind Games, 20.

${ }^{8}$ Caplan, Mind Games, 21-3, and Mark S. Micale, "Charcot and the Idea of Hysteria in the Male: Gender, Mental Science, and Medical Diagnosis in Late Nineteenth-Century France," Medical History 34 (1990), 363411, especially 370-1, 385-91, 406-8. As Micale observes, the extent to which Charcot progressed toward psychogenic explanations of hysteria is a topic of dispute, but while he clung to neurophysiological etiologies, he seems to have "moved timidly toward psychogenic explanations through his work on select topics." In several instances these topics included male hysteria (Micale, 391 n. 118). For additional histories of the development of the diagnosis of male hysteria, and Charcot's role in this, 
see Elaine Showalter, Hystories: Hysterical Epidemics and Modern Culture (New York: Columbia University Press, 1997), 62-77; Frank J. Sulloway, Freud, Biologist of the Mind: Beyond the Psychoanalytic Legend (New York: Basic Books, 1979), 30-41; Henri F. Ellenberger, The Discovery of the Unconscious: The History and Evolution of Dynamic Psychiatry (New York: Basic Books, 1970), 438-42; and Christopher G. Goetz, Michel Bonduelle, and Toby Gelfand, Charcot: Constructing Neurology (New York: Oxford University Press, 1995), 202-3.

${ }^{9}$ See George Frederick Drinka, The Birth of Neurosis: Myth, Malady, and the Victorians (New York: Simon and Schuster, 1984), 114-16; and Michael Roth, "Hysterical Remembering," Modernism/Modernity 3, no. 2 (1996), 1-30, 2-4. Henry Maudsley, in 1870, insisted on a similarly physical model of shock as causing "commotion in the molecules of the brain" (Body and Mind, 94). Also see Matus's essay in this volume, "Emergent Theories of Victorian Mind Shock," for an excellent account of theories of nerve force as electrical and for another instance, in George Eliot's Middlemarch (1871-72), connecting mental shock to electrical shock.

${ }^{10}$ Ellenberger, The Discovery of the Unconscious, 90-1, 148, 438-9; also Sulloway, Freud, Biologist of the Mind, 30, 33-34.

${ }^{11}$ Roger Smith, Inhibition: History and Meaning in the Sciences of Mind and Brain (Berkeley: University of California Press, 1992), 75.

${ }^{12}$ See John Furneaux Jordan, "On Shock After Surgical Operations and Injuries," Special Enquiries; Including the Hastings Essay on Shock, the Treatment of Surgical Inflammations, and Numerous Clinical Lectures, $2^{\text {nd }}$ ed. (London: J. A. Churchill, 1881), 1-60. Further references will be cited parenthetically in the text as SASO.

${ }^{13}$ Smith, Inhibition, 76, 80-3.

${ }^{14}$ On this development in the thought, especially, of Bain and Spencer, see Robert M. Young, Mind, Brain and Adaptation in the Nineteenth Century: Cerebral Localization and its Biological Context from Gall to Ferrier (New York: Oxford University Press, 1990), and Rick Rylance, Victorian Psychology and British Culture 1850-1880 (New York: Oxford University Press, 2000). Also see Peter Amacher, "Freud's Neurological Education and its Influence on Psychoanalytic Theory," Psychological Issues 4, no. 4 (1965), 21-28, on the brain anatomist Theodore Meynert's theories about the "arciform bundles" and "association fibres"—nerve bundles in the brain's white matter-as forming the basis for mental associations.

${ }^{15}$ Théodule Ribot, The Diseases of Memory (New York: J. Fitzgerald, 1883), $2,7$.

${ }^{16}$ F. G. Gosling, Before Freud: Neurasthenia and the American Medical Community, 1870-1910 (Urbana and Chicago: University of Illinois Press, 1987), 132.

${ }^{17}$ See, especially, George Chauncey, Jr., "From Sexual Inversion to Homosexuality: The Changing Medical Conceptualization of Female 'Deviance,"' in Kathy Peiss and Christina Simmons, eds., Passion and Power: Sexuality in History (Philadelphia: Temple University Press, 1989), 87-117, and John Marshall, "Pansies, Perverts and Macho Men: 
Changing Conceptions of Male Homosexuality," in Kenneth Plummer, ed., The Making of the Modern Homosexual (Totowa, N.J.: Barnes and Noble, 1981), 133-54. But also see Jeffrey Weeks, Coming Out:

Homosexual Politics in Britain, from the Nineteenth Century to the Present (London: Quartet Books, 1977), especially the first two chapters; Neil Miller, Out of the Past: Gay and Lesbian History from 1869 to the Present (New York: Vintage, 1995), especially chapter two, "Pioneers of Sexology"; John D'Emilio and Estelle B. Freedman, Intimate Matters: A History of Sexuality in America (New York: Harper and Row, 1988), 121-2; Jonathan Ned Katz, Gay/Lesbian Almanac: A New Documentary (New York: Harper and Row, 1983), especially 139-57; and Francis Mark Mondimore, A Natural History of Homosexuality (Baltimore: Johns Hopkins University Press, 1996), 34-49.

${ }^{18}$ Harry Oosterhuis, Stepchildren of Nature: Krafft-Ebing, Psychiatry, and the Making of Sexual Identity (Chicago and London: University of Chicago Press, 2000); Vernon A. Rosario, The Erotic Imagination: French Histories of Perversity (New York: Oxford University Press, 1997), 84. Of course, these scholars build on the history of the medicalization of homosexuality laid out by Michel Foucault in The History of Sexuality, Volume I: An Introduction (New York: Random House, 1980), 43.

${ }^{19}$ The essays by Americans are: E. C. Spitzka, "A Historical Case of Sexual Perversion," Chicago Medical Review 4, no. 4 (20 August 1881), 378-79; G. Alder Blumer, "A Case of Perverted Sexual Instinct," American Journal of Insanity 39 (July 1882), 22-35; James G. Kiernan, "Insanity. Lecture XXVI.-Sexual Perversion," Detroit Lancet 7, no. 11 (May 1884), 481-4; James G. Kiernan, "Perverted Sexual Instinct," Chicago Medical Journal and Examiner 48 (1884), 263-5 (actually a report on a paper read by Kiernan), and J. C. Shaw and G. N. Ferris, "Perverted Sexual Instinct," Journal of Nervous and Mental Disease 10, no. 2 (April 1883), 185-204. William M. Hammond, Sexual Impotence in the Male (New York: Birmingham, 1883) also devotes substantial attention to "perversion of the sexual appetite" and to pederasty as causes of heterosexual impotence.

${ }^{20}$ See J. C. Shaw and G. N. Ferris, "Perverted Sexual Instinct," which helpfully summarizes previously reported cases.

${ }^{21}$ Jean-Martin Charcot and Valentin Magnan, "Inversion du sens génital," Archives de Neurologie 3 (1882), 53-60; and 4 (1882), 296322.

${ }^{22}$ Mark S. Micale plausibly suggests that Charcot, wanting to legitimize his diagnostic category of masculine hysteria, purposely kept it separate from homosexuality, so that male hysterics would not be marginalized as effeminate or as homosexual. Since, for Charcot, traumatic hysteria was so closely identified with male hysteria, this may have been the reason for not bringing trauma together with sexual inversion. See Micale, "Charcot and the Idea of Hysteria in the Male," 381-2.

${ }^{23}$ Rosario, The Erotic Imagination, 85-9.

${ }^{24}$ Ian Dowbiggin, "Back to the Future: Valentin Magnan, French Psychiatry, and the Classification of Mental Diseases, 1885-1925," Social History of Medicine 9, no. 3 (1996), 383-409, 389-94. 
${ }^{25}$ Kiernan, "Insanity. Lecture XXVI.-Sexual Perversion," 481.

${ }^{26}$ Blumer, "A Case of Perverted Sexual Instinct," 35.

${ }^{27}$ Hammond, Sexual Impotence, 62-3, referring to a "decided inversion of the sexual feeling" in a patient who preferred the passive position in anal intercourse.

${ }^{28}$ Shaw and Ferris, "Perverted Sexual Intinct," 190, 195, 199, 200.

${ }^{29}$ Hammond, Sexual Impotence, 35-6.

${ }^{30}$ Pierre Janet, L'automatisme psychologique (Paris: Alcan, 1889), 439. Ian Hacking provides a narrative of the psychologization of trauma that includes Janet's cases of reliving and revising traumatic memories and moves to Freud's (and Breuer's) method of the talking cure. Hacking also places Janet's work around 1888, and Freud, only in 1888, airs the idea of having a patient return in hypnosis to the traumatic event in order to cure it; Holmes's cure through reliving the trauma still predates both. See Hacking, Rewriting the Soul, 183-95.

${ }^{31}$ Quoted in Malcolm Macmillan, Freud Evaluated: The Completed Arc (Cambridge, Massachusetts: MIT Press, 1997), 77. As Macmillan reports, Delboeuf described his case in Revue de Belgique (15 November 1888) — with three succeeding parts, all published together as a book in 1889. Delboeuf's book, Le magnetisme animal, is reviewed in Mind 14 (1889), 470-1.

${ }^{32}$ Edward Bellamy, Dr. Heidenhoff's Process (1880; reprint New York: AMS Press, 1969), 96, 100-1, 110.

${ }^{33}$ Hacking, Rewriting the Soul, 195-6. 